\title{
Clérigos, lavadores y traficantes: El caso de los narco diezmos
}

\author{
David Muñoz Condell ${ }^{1}$
}

\begin{abstract}
Resumen
El artículo presenta las relaciones posibles entre narcotráfico e Iglesias, para ello revisa casos actuales en nuestro país en donde esta relación estaría presente. También se analizan casos fuera de Chile, en donde esta situación se presenta con mayor fuerza y es parte de la operación cotidiana de las mafias de la droga presentes en esos casos.
\end{abstract}

Palabras clave: Iglesias, Narcotráfico, Diezmos, Mafia.

\begin{abstract}
The article presents the possible relationships between drug trafficking and churches, for that review current cases in our country where this relationship would be present. Also included are cases outside of Chile, where this situation occurs with greater force and is part of the daily operation of the drug gangs present in these cases.
\end{abstract}

Key words: Iglesias, Drug Trafficking, Tithes, Mafia.

1 Pastor Bautista. Licenciado en Ciencias del Desarrollo, ILADES. Doctor en el Estudio de las Sociedades Latinoamericanas, mención Sociología, Universidad ARCIS. Profesor Ayudante del Director General de la PDI, Sr. Arturo Herrera Verdugo, en la Cátedra de Ética del Mando de la Academia Superior de Estudios Policiales y Capellán Nacional Evangélico de la PDI. 


\section{Presentación}

El tráfico ilícito de drogas, problemática que alcanza todos los estamentos de nuestra sociedad, se reconoce hoy como un fenómeno global y su avance se atribuye a diversos indicadores sociales. $^{2}$

El Director General de la Policía de Investigaciones de Chile (PDI), Sr. Arturo Herrera Verdugo: dice al respecto que "se sabe que el desarrollo de un país, junto con abrir alternativas para mejorar la calidad de vida y representar un mejoramiento de las oportunidades para las personas, también trae consigo la emergencia de nuevos riesgos. La paradoja del desarrollo de la sociedad radica en la vulnerabilidad frente a amenazas imprevistas". ${ }^{3}$

En palabras de Clara Szczaranski, "el delito moderno usufructúa de la amplitud de los mercados, de los avances tecnológicos, de las fronteras abiertas y de la profusión de posibilidades de comunicación instantánea y anónima. Mercados sin límites geográficos, hemos dicho, van a la par de crímenes sin fronteras". ${ }^{4}$

En este contexto, las estrategias tanto nacionales como internacionales de las organizaciones criminales desafían a la sociedad civil con innovadoras formas de estructuras, sistemas comunicacionales y canales de distribución, que han corrompido a instituciones tan prestigiosas como son las organizaciones eclesiásticas y sus ministros que han sucumbido a los tentáculos de las "narco ofrendas" o los "narco diezmos" que debilitan la característica de sentido moral que tienen las iglesias. ${ }^{5}$

2 Manuel Castell. Globalización, Desarrollo y Democracia: Chile en el Contexto Mundial. Fondo de Cultura Económica. Santiago. Chile. 2005.

3 Arturo Herrera Verdugo. Cuenta Pública $71^{\circ}$ Aniversario de la Policía de Investigaciones de Chile. Santiago. Chile. 19 de junio 2004.

4 Clara Szczaranski. La Delincuencia Moderna, Prólogo del libro de Manuel Salazar. Conexiones Mafiosas: El Crimen Organizado a las Puertas de Chile. Sociedad Editorial Momentum. Santiago. Chile. $1^{\circ}$ edición. Julio 2008. Página 1.

5 Las iglesias son vistas como organizaciones sociales que dan sentido moral a la sociedad. Por lo que al verse involucradas en conexiones mafiosas pierde el sentido de referente ético en una sociedad donde los sinsentidos se posesionan cada vez más. David Muñoz Condell. Ética, Modernidad y Postmodernidad. Documento de 
En el mes de julio de 2008 el país es sorprendido con un titular de uno de los diarios de mayor circulación de Chile, como lo es La Tercera, que en su edición del 23 de julio de 2008 titulaba: "Banda de narcotráfico financiaba templo evangélico y colegio". En dicha oportunidad la PDI desarticulaba una de las bandas de narcos más poderosas de la historia criminal criolla.

“Los hermanos Carte controlaban un próspero negocio de $\$ 1.000$ millones y se dedicaron a permear el tejido social de su comuna en busca de apoyo. Daban suculentas donaciones y financiaban fiestas. A cambio, escondían bien el origen de sus ganancias". ${ }^{6}$ Siendo "este grupo uno de los máximos proveedores de droga de la zona sur de la capital, internaban cerca de 100 kilos de coca al mes y tenían entre sus clientes a "Los Cavieres", de la población La Victoria"7.

Consultado uno de los dirigentes sociales del sector, el Sr. Víctor Cuevas, quien comenta "que aún no sale del asombro con la detención del Pastor Patricio Araya, quien estaba a cargo del Centro de Formación Cristiana Renacer en Cristo de El Bosque, acusado de actuar como testaferro de la banda "Los Guatones". La cercanía de los líderes del grupo, Sergio y Víctor Carte Rivas, con redes sociales y religiosas de la comunidad era uno de los pilares de la organización que abastecía de cocaína a bandas de la capital, como "Los Cavieres". 8 "Ambos hermanos comenzaron como microtraficantes en la población Marina de Gaete, en El Bosque. A poco andar, crearon su red con círculos familiares y vecinales, por lo que la mayor parte de sus colaboradores son sus vecinos en El Bosque. Otro punto en común, comentan los periodistas del dia-

Trabajo $\mathrm{N}^{\mathrm{o}}$ 111. Escuela de Investigaciones Policiales. Santiago. Chile. Noviembre 2005.

6 Felipe Díaz Prieto y Andrés López. Banda de Narcotráfico financiaba templo evangélico y colegio. Sección Nacional. Diario La Tercera. Santiago. Chile. 23 de julio del 2008. www.latercera.cl. Fecha de Acceso 24 de julio de 2008. 17:30 horas.

7 Claudio Leiva Cortés. Cae Banda que proveía de cocaína a $\bigotimes$ Los Cavieres $\bigotimes$. Diario La Nación. Santiago Chile. www.lanacion.cl. Fecha de Acceso: jueves 24 de julio de 2008. 22:00 horas.

8 Ibíd. 
rio La Tercera, es que casi todos los miembros profesan la religión evangélica y se llamaban "hermanos", entre sí".

De hecho, la investigación policial realizada por la PDI en conjunto con la Fiscalía Occidente fue bautizada como "Operación Hermandad" por su relación eclesiástica con el Pastor Patricio Araya, a quien periódicamente le entregaban diezmos de unos $\$ 100$ mil y ayudaron a principios de 2007 a remodelar el templo"10.

Por otra parte, el decano del periodismo chileno, El Mercurio, informaba al respecto sobre los hermanos Carte Rivas... "hacían fuertes contribuciones a la iglesia evangélica "Centro de Formación Cristiana Renacer en Cristo", ubicada en la esquina de Vecinal Norte con San Francisco, de la comuna de El Bosque... ésta era liderada por el Pastor Patricio Alberto Araya Pulgar... y también fue acusado de participar como testaferro de la organización, pues tenía varios bienes a su nombre. Él fue arrestado junto con su pareja Mary Palma... De acuerdo a lo informado, tanto Araya Pulgar como su pareja serán formalizados por el delito de lavado de dinero". ${ }^{11}$

Esta organización criminal contaba con gran cantidad de armamento y municiones de distinto calibre, que utilizaban para resguardo de sus operaciones de narcotráfico. La PDI al momento de la detención incautó 42 kilos de clorhidrato de cocaína y 11 millones de pesos en dinero en efectivo, con 19 imputados detenidos. ${ }^{12}$

A lo anterior, es necesario citar los vínculos que tenían "los Guatones" con "los Cavieres ó Care jarro". Esta organización cri-

9 Ibíd.

10 Ibíd.

11 F. Águila, O. Saavedra, P. Reed. Los Movimientos, Contactos y Roles de los Miembros de la Banda de los $₫$ Guatones $\bigotimes$. Captura de Organización Proveedora de Cocaína en la Zona Sur de Santiago. www.el mercurio.com. Santiago. Chile. Fecha de Acceso: jueves 24 de julio 2008. 19:40 horas.

12 David Mesa. Cuenta Pública 2007-2008, Jefatura Nacional Antinarcóticos. Policía de Investigaciones de Chile. Santiago. Chile. 29 de julio 2008. 
minal operaba en la población la Victoria. Su líder, Alejandro Cavieres Alarcón, alias "care jarro", junto a su grupo familiar y amigos cercanos, traficaban cocaína al interior de la misma, adquirida en la zona norte del país, y posteriormente comercializada en la zona sur de la capital. Los Cavieres contaban con armamento de alto poder de fuego, para su protección contra bandas rivales. La PDI puso a disposición del Ministerio Público 20 personas, siendo formalizadas; por tráfico de drogas, asociación ilícita, porte ilegal de armas y lavado de dinero..$^{13}$

\section{Claves mafiosas y presencia en Chile}

La Jefatura Nacional Antinarcóticos de la PDI reveló en su última Cuenta Pública que entre el segundo semestre del año 2007 y el primer semestre de 2008 fueron puestas a disposición del Ministerio Público 6.294 personas en calidad de imputados por infracción a la Ley 20.000 que sanciona el tráfico ilícito de estupefacientes y sustancias sicotrópicas. ${ }^{14}$ Entre sus logros en materias de incautación y desarticulación de organizaciones y bandas criminales, al primer semestre de 2008 se enumera: una tonelada de clorhidrato de cocaína, equivalente a 4.447 .760 dosis; dos toneladas de cocaína base, equivalente a 9.619.250 dosis; tres toneladas y media de cannabis sativa procesada, equivalente a 7.329.484 dosis; 2.567 unidades de éxtasis; 8.308 unidades de fármacos, y 21 dosis de LSD.

Además, este primer semestre de 2008 se desarticularon 24 bandas criminales pertenecientes a diferentes comunas de Santiago (un 40\% más que el primer semestre de 2007), y se detuvieron 191 personas (un 16\% más que el primer semestre de 2007). Un hecho no menor tiene que ver con la detención de 29 ciudadanos extranjeros pertenecientes a estas bandas, lo que representa un $63 \%$ de aumento en comparación con el año anterior. Esta gestión de la PDI nos da pie de que en nuestro país se está atacando con

13 Ibíd.

14 Ibíd. 
éxito al crimen organizado y que la policía ya no sólo va tras el micro tráfico, sino que también sobre el macro tráfico.

El periodista chileno Manuel Salazar en su libro "Conexiones Mafiosas: el Crimen Organizado a las Puertas de Chile"15 presenta antecedentes esclarecedores sobre esta nueva criminalidad que ya es parte de las nuevas realidades y temores con que debemos vivir en nuestro país. Manuel Salazar publicó en 1996 otra obra que se titula: "Traficantes y Lavadores"16, que trata sobre la evolución de esta problemática delincuencial en Chile y en los países del Cono Sur, como son: Argentina, Paraguay, Uruguay, Perú, Bolivia y Brasil. "A través de este estudio uno se explica muchas cosas que tienen que ver con política internacional, con la economía, con flujos monetarios y el auge de determinados mercados gracias al lavado de dinero. Las inversiones que llegan a Chile provenientes de los paraísos fiscales nadie los controla. En América Latina sobre todo, nadie se preocupa", explica Manuel Salazar. ${ }^{17}$

Sin embargo, lo más inquietante de lo que está sucediendo en nuestro país es la creciente criminalidad juvenil ${ }^{18}$, cada vez de carácter y accionar más violentos, lo que genera prácticas delictuales en los jóvenes con altos índices de causa de muerte por uso de armas blancas y armas de grueso calibre.

La criminalidad juvenil ${ }^{19}$ creciente tiene muchas aristas. "Hoy vas a las poblaciones y a los barrios periféricos de la capital chilena y observas estacionados en modestas casas a vehículos

15 Manuel Salazar. Conexiones Mafiosas: El Crimen Organizado a las Puertas de Chile. Sociedad Editorial Momentum. Santiago. Chile. $1^{\mathrm{a}}$ edición, julio 2008.

16 Manuel Salazar. Traficantes \& Lavadores. Ediciones Grijalbo. México. 1996.

17 Ver a Mats Berdal y Mónica Serrano (compiladores). Crimen Transnacional Organizado y Seguridad Internacional: Cambio y Continuidad. Fondo de Cultura Económica. México. 2005.

18 VVAA. Prevención de la Delincuencia Juvenil. Análisis de experiencias internacionales. División de Seguridad Ciudadana, Ministerio del Interior. República de Chile. Universidad Alberto Hurtado. 1a edición. Santiago. Chile. Marzo 2004.

19 Ver a Doris Cooper. Delincuencia y Desviación Juvenil. $1^{\text {a }}$ edición. Ediciones LOM. Santiago. Chile. 2005. 
4x4, que valen sobre los 25 millones. Los narcos salen a carretear al sector alto, a Viña del Mar. El modelo de desarrollo social celebra eso: hay que ostentar lo que se tiene y los narcos lo llevan a su máxima expresión. Ya no es como antes que el delincuente de la pobla trataba de pasar "piola", "inadvertido". Hoy ves soldados (protectores), mucho vehículo, tienen caballos de carrera, imagínate lo que va a ocurrir ahora con la proliferación de casinos". ${ }^{20}$ Entre tanto anuncio negativo, Manuel Salazar hace uno positivo: el control de la pasta base. Y lo atribuye a una fuerte baja en la demanda por las nefastas consecuencias y daños que le ocasionan al consumidor.

“La pasta base surgió en Chile cuando a Horacio Toro, el primer Director de Investigaciones en democracia, se le ocurrió hacer quemar todas las plantaciones de marihuana del valle del Aconcagua. Ahora ha aumentado el consumo de marihuana, el de cocaína se mantiene estable pero lo que está creciendo de manera desorbitada son las drogas sintéticas, pastillas que producen todo tipo de sensaciones. Es lo que está de moda en Europa y es el mercado al cual también se están inclinando los estadounidenses. En especial por la facilidad de la producción. Puedes fabricarla en el baño de tu casa. No requieren tantos elementos químicos y productos como la cocaína".

Destaca que nuestra policía no es corrupta, pero el riesgo está, porque faltan recursos para contrarrestar a las bandas organizadas. "Dentro de Los Gaete y Los Guatones hay peruanos, bolivianos, colombianos y venezolanos, es evidente que existen los vínculos internacionales, pero hasta ahora son proveedores, hacen los contactos, y aparentemente no han tratado de instalarse en Chile. El principal cartel mexicano estuvo instalado y alcanzaron a detectarlo. Lo que está pasando en Chile se revela en casos como el de una carnicería en Quinta Normal, es pequeña, no muy grande, y si vas un jueves en la tarde, viernes al mediodía y

20 Manuel Salazar. Conexiones Mafiosas: El Crimen Organizado a las Puertas de Chile. Sociedad Editorial Momentum. Santiago. Chile. $1^{\mathrm{a}}$ edición. Julio. 2008. 
te topas con BMW, Mercedes Benz, y esas personas no van a comprar carne. Ese carnicero es protector de dos o tres poblaciones, compra las camisetas para el club deportivo, provee las fiestas de la comisaría y de los rati, le consigna pega a la gente que queda cesante, ayuda a la abuelita que se le murió el marido, organiza la fiesta para los niños más pobres y se transforma en una especie de protector. Es un personaje cuidado además por todos los vecinos. Esto tal cual ocurrió en Colombia cuando empezaron los carteles, cuando mataron a Pablo Escobar era como si hubieran matado un héroe". ${ }^{21}$

Combatir el crimen organizado requiere de mucho dinero. "Los italianos destinarán 10.000 millones de euros para derrotar a la mafia y ¿de dónde los van a sacar? De los bienes confiscados a los narcotraficantes. Todos los bienes que se incautan se rematan y van a ese fondo. En Chile, los autos del Cabro Cabrera que fueron incautados siguen en los patios destinados a ese fin. Lo mismo pasa con las casas, los caballos de carrera, etc., porque la legislación les permite interponer todo tipo de recursos para impedir los remates". ${ }^{22}$

La ex Presidenta del Consejo de Defensa del Estado, abogada Clara Szczaranski, llama a esta nueva criminalidad de la siguiente forma: "creo razonable llamar crímenes trascendentes a los delitos de los tráficos organizados -drogas, armas, personas, órganos humanos entre otros-, y a los delitos que perpetran las empresas que operan con productos y servicios lícitos de manera ilícita... Hoy es menester dar espacio a la consideración de nuevos sujetos peligrosos: organizaciones criminales y personas

21 Ibíd.

22 Jean-François Gayraud, uno de los mejores especialistas franceses en nuevas formas de criminalidad, da respuesta a éstas y otras muchas cuestiones en su nueva obra, editada por Urano El G9 de las mafias en el mundo. Un libro imprescindible para comprender el funcionamiento interno de una mafia, así como el peligro real que representa en la actualidad. Un estudio ampliamente documentado. El autor es comisario divisionario de la Policía francesa, doctor en Derecho, y diplomado por el Institut d'Études Politiques y por el Instituto de Criminologia, ambos de París. Jean Francois Gay Raud. El G 9 de las Mafias en el Mundo, Geopolítica del Crimen Organizado. Ediciones Urano. Barcelona, España. 
jurídicas, considerando, además, que las organizaciones criminales también utilizan personas jurídicas para disimular su operar. Estas entidades, plurales, organizadas y jerarquizadas, debieran llegar a constituir el centro de atención de las modernas políticas públicas y, particularmente, de nuestra política de Estado en lo criminal". ${ }^{23}$

En la actualidad, una de las actividades criminales de mayor importancia a nivel mundial es la organización criminal, las que ofrecen en este sentido un sinfín de oportunidades que dan un status y un rango en la estructura de estas mismas, lo que hace preocupante para la función pública, el desarrollo de la investigación y descubrimiento de estas actividades que día a día crecen y surgen nuevas formas de comisión de estos, los que cada vez hacen más dificultosa la acción penal y la persecución en su contra, por la magnitud y creatividad que conlleva la realización de estas actividades ilícitas. ${ }^{24}$

La actividad que estas organizaciones realizan son de gran relevancia a nivel mundial, lo que genera por parte de las policías, una gran preocupación; por lo que debemos saber qué significan cada uno de los códigos que ocupan y los términos que utilizan, las actividades que llevan a cabo y sin lugar a dudas las áreas de poder en los que ejercen poder coercitivo y coaccional, ya que sin lugar a dudas este tipo de organizaciones es muy dañina para toda la actividad de desarrollo de un país y lleva consigo la realización de actividades anexas para conseguir sus objetivos, como: terrorismo, lavado de dinero, robos, incendios, daños y estragos, homicidios encubrimientos, abusos de confianza.

23 Clara Szczaranski. La Delincuencia Moderna. Prólogo del libro de Manuel Salazar. Conexiones Mafiosas: El Crimen Organizado a las Puertas de Chile. Sociedad Editorial Momentum. Santiago. Chile. $1^{\mathrm{a}}$ edición, julio 2008. Página 3.

24 En nuestro país existen diferentes tipos de delitos, pero hablar de Crimen Organizado en sí es un tema complejo, ya que la legislación chilena no contempla una definición de "Crimen Organizado", el tipo penal que más se asemeja es el de ASOCIACIÓN ILíCITA, contemplado en nuestro Código Penal. Ver artículos 292 al 295 del Código Penal de la República de Chile. Www.servicioweb.cl/juridico. Fecha de Acceso: jueves 18 de septiembre de 2008. 19:45 horas. 
Y muchas más que sin lugar a dudas afectan directamente el desarrollo del país y la evolución de la actividad de un determinado lugar, sin dejar de lado lo que en lo policial nos concierne, que es el ejercer el control del delito, la corrupción ${ }^{25}$ que afecta diariamente todo el desarrollo y la imagen pública de las instituciones y los funcionarios que se encuentran involucrados en estas malas obras, además de la persecución penal de los delitos que afectan nuestro país.

\section{Definiciones de crimen organizado}

Existen varias teorías al respecto, siendo las más relevantes la americana, que nace de la época de la prohibición en los años '20 y fue utilizado principalmente para definir la actividad que realizaban los traficantes de alcohol ilegales, más conocidos como los Bootleggers.

La Unión Europea crea una definición de 11 criterios de los cuales 6 a lo mínimo son necesarios para que exista y se constituya el crimen organizado. ${ }^{26}$

Estos 11 criterios son: 1) Colaboración de dos o más personas. 2) Tareas específicas de cada una de las personas. 3) Sobre un período de tiempo bastante largo o determinado. 4) Con un tipo de disciplina o control. 5) Personas sospechosas de ya haber cometido infracciones penales graves. 6) Actuando a nivel internacional. 7) Utilizando la violencia u otros tipos de intimidación. 8) Utilizando estructuras comerciales o de otro tipo comercial. 9) Dedicándose al blanqueo de dinero. 10) Ejerciendo una influencia sobre los medios políticos, de información, administración pública, el poder judicial o la economía. 11) Actuando para el dinero $\mathrm{y} / \mathrm{o}$ el poder.

25 Vera a Peter Eigen. Las Redes de la Corrupción: La Sociedad Civil Contra los Abusos del Poder. $1^{\text {a }}$ edición. Editorial Planeta. Buenos Aires. Argentina. Septiembre de 2004.

26 Isabel Sánchez García de Paz La Criminalidad Organizada. Aspectos Penales, Procesales, Administrativos y Policiales. Dykinson. España. 2005. 
Las Naciones Unidas en la Convención contra la Criminalidad Transnacional Organizada en Palermo el 2000, crea la definición de "Grupo Criminal Organizado", diciendo al respecto que: "Es un grupo estructurado de personas de tres o más integrantes, que existe desde un cierto tiempo, y actúa conjuntamente para cometer una o más infracciones graves o para sacar de ellas, directa o indirectamente, una ventaja financiera $u$ otra ventaja material". ${ }^{27}$

En relación a la criminalidad, sostienen que son hechos que revisten caracteres de delitos graves, es decir de aquellos que sobrepasan la pena de presidio mayor en su grado mínimo, siendo así su pena en años mayor a 5 años. Generalmente los tipos de criminales que conforman estas organizaciones son sujetos de un alto nivel intelectual que manejan todo con suma frialdad y cálculo.

Con respecto a sus ganancias, son de varios tipos. Estas organizaciones no buscan solo satisfacerse de manera económica sino que, además, con el daño y los estragos que pueden causar a una persona o un grupo social.

Existen dentro de estas ganancias en relación directa con la criminalidad:

- Criminalidad sin ganancias: Estas no buscan obtener bienes materiales sino que la mera proporción de daño a sus víctimas a través de golpes y heridas, homicidios, incendios, degradaciones de edificios, infracciones menores.

- Infracciones cuyo perjuicio corresponde a víctimas: Aquí no solo es el daño a la víctima sino que también la obtención de beneficios y/o ganancias para el victimario (os). Robos, encubrimientos, abusos de confianza y estafas.

27 Sandro Calvani. Rol de las Naciones Unidas (UNODC) en la lucha contra la delincuencia organizada transnacional, el terrorismo y la corrupción. www. sandrocalvani.com. Fecha de Acceso: miércoles 17 de septiembre de 2008. 17:10 horas. 
- Infracciones organizadas cuyas ganancias son considerables y regulares: Son aquellas cuyo beneficio representa el mayor sustento para la organización, es el fin por el cual realizan todas sus actividades ilícitas, ya que con ellas pueden obtener fuertes sumas de dinero y por medio de lo cual obtienen poder, a través del tráfico de drogas ${ }^{28}$, tráfico de armas, proxenetismo, delincuencia financiera, entre otras.

Las actividades criminales tradicionales que realizan este tipo de organizaciones criminales son: Tráfico de armas, narcotráfico, tráfico de objetos de arte, tráfico humano, contrabando, Extorsión y secuestro, terrorismo, juegos clandestinos, falsificación de dinero, robos a mano armada, robo de vehículos, manipulación de servicios públicos. ${ }^{29}$

\section{Etapas de la ascensión criminal}

Las etapas de ascenso dentro del ámbito criminal son determinadas por niveles de crecimiento, los que a medida que se cumple con ciertos requisitos pueden llegar a convertirse en organizaciones criminales o más que eso. Estos niveles son llamados y enumerados de la siguiente forma: Inicio de la Carrera Criminal, Crímenes con Estructura y Capital, Necesidad de Ganancias Estables, Infiltración dentro de la Economía Legítima, Actividades contra la Sociedad y el Estado, Carteles y Organizaciones Criminales Análogas y Mafias. ${ }^{30}$

\section{Niveles de Criminalidad}

Primer Nivel. Sus actividades se caracterizan por el proxenetismo, robos a mano armada, y microtráfico. Los individuos que

28 Alejandro Goic Karmelic. La Iglesia ante la Droga. Conferencia Episcopal de Chile. Santiago. Chile. 28 de junio 2008.

29 David Muñoz Condell. Ética Pública en Manual de Ética. Cuadernos de Criminología. Policial de Investigaciones de Chile. Santiago. Chile. 2004.

30 Ver a Rafael Pardo Mateos. Fenomenología del Delito: Delincuencia Tradicional y Nuevas Formas de Delincuencia. En VVAA. Elementos Básicos de Investigación Criminal. Instituto Universitario General Gutiérrez Mellado de Investigación sobre la Paz, la Seguridad y la Defensa. Madrid. España. 2007. 
participan aquí son brutales y con calidades primitivas (astucia, la desconfianza y demarcación territorial). El nivel de asociación de este tipo de criminales es impulsivo y discontinúo, son grupos temporales y poco estructurados de amigos de barrio y primos de un clan. Permite la acumulación primitiva de capital, muchos de los grupos que se forman quedan en este nivel y la minoría de estos asciende en la escala criminal.

Segundo Nivel. Sus actividades son organizadas, continuas y durables. El tráfico de drogas es local o regional, venta de vehículos robados, tragamonedas y loterías ilegales, robos a mano armada. Su perfil se caracteriza por las capacidades jerárquicas, administración de un territorio, concepción de contra-medidas (corrupción, intimidación y violencia.). Su estructura se caracteriza por establecer una verdadera empresa criminal implicando cómplices, abogados, notarios, notabilidades corruptas.

Tercer Nivel. En este nivel los criminales ya tienen una vida lujosa y ostentan de su riqueza, tienen además necesidad de un flujo constante de dinero en efectivo (extorsión y chantaje). Son individuos lúcidos, realistas y planificadores.

Cuarto Nivel. Ocupan el reciclaje de dinero criminal dentro de la economía y las finanzas legítimas. Cuentan además con la adquisición de pequeños comercios o empresas que sirven de fachada legal y cobertura, de soporte de la actividad criminal (blanqueo, compra o transacción de bienes a uso criminal). Además deben pasar por niveles de aprendizaje para llegar a niveles superiores.

Quinto Nivel. Realizan todas las operaciones criminales. Gracias a una cobertura económica y una representación social marcada, permite acceder a la gran delincuencia financiera: Facturas falsas, estafas comerciales, fraudes en perjuicio del Estado y desvíos de subvenciones. 
Sexto Nivel. Organizaciones Criminales Transnacionales. Aquí en este nivel ya las actividades realizadas son de carácter transnacional, Administran un imperio legalizado a través de prestanombres. Son controladores de su propio territorio. Poseen nexos directos con las instituciones y los medios de negocios. Utilizan niveles de criminalidad relacionando además la corrupción, intimidación, eliminación. Es un conjunto de individuos, sociedades comerciales, en ocasiones asociaciones privadas, con status muy diversificados.

Los Tipos de Organizaciones Criminales Transnacionales más conocidos son: Los Holdings: organización tal como la mafia italiana que reagrupa numerosos sectores de actividades (extorsión de fondos, secuestros, tráfico de todo tipo, juegos clandestinos, lavado de dinero, etc.). Poseen una estructura lineal; y Los Carteles: Organización que reagrupa todas las fases de una misma actividad, tal como los carteles colombianos, que controlan la producción de las hojas de coca, su transformación en pasta base, luego en cocaína y la distribución mayorista y medio mayorista, hasta a veces la distribución de detalles, tal como en los EE.UU. Esta industria de la cocaína supone una organización estructurada, jerarquizada y piramidal.

Séptimo Nivel. Las Mafias. Estas son sociedades secretas permanentes con ritos de iniciación e integración (compartimentadas y jerarquizadas con reglas de vida estricta). Tienen una noción de clan o familia. A menudo en perfecta simbiosis con oligarquía financiera y política. Controlan su territorio (barrio, ciudad, región, país) al utilizar la violencia como estrategia de hegemonía.

\section{La iglesia y las narco ofrendas del crimen organizado}

Los Obispos de la Provincia Eclesiástica de Acapulco en respuesta a la violencia que deriva de las organizaciones criminales y el deterioro de la vida social, redactaron una carta pastoral sobre 
el crimen organizado en la ciudad de Guerrero, el 24 de enero de 2008, diciendo que: "todas las formas de crimen organizado implican una verdadera idolatría en cuanto que expresan, ya de manera consciente o inconsciente una decisión contraria a la Ley de Dios. No sólo se rechazan las leyes humanas establecidas para cuidar el bien común, sino que se rechaza, también, al mismo Dios. El crimen organizado manifiesta una verdadera idolatría en la que la fascinación por el poder que ofrece el dinero sustituye la adoración al verdadero Dios. Bien decía el Señor, "no pueden ustedes servir a Dios y al dinero", cuando proponía la alternativa de la verdadera fe que excluye toda clase de idolatría, que excluye siempre al verdadero Dios" ${ }^{\prime \prime 1}$.

En los últimos años ha recrudecido en nuestra región, comentan los obispos mexicanos, la violencia causada por organizaciones criminales, distinta a la violencia intrafamiliar y a la violencia causada por la delincuencia común en las calles.

Esta violencia tiene sus propias características, sus causas y sus circunstancias. Está marcada por la crueldad, por el ajuste de cuentas, por la exhibición de poder y por la intención de intimidar a los rivales y a toda la sociedad. Esta situación no es exclusiva de nuestra región. Los obispos latinoamericanos han señalado recientemente que "la vida social se está deteriorando gravemente en muchos países de América Latina y del Caribe por el crecimiento de la violencia, que se manifiesta en robos, asaltos, secuestros, y lo que es más grave, en asesinatos que cada día destruyen más vidas humanas y llenan de dolor a las familias y a la sociedad entera.

La violencia reviste diversas formas y tiene diversos agentes: el crimen organizado y el narcotráfico, grupos paramilita-

31 Carta Pastoral sobre el Crimen Organizado en Guerrero. Mensaje de los Obispos de la Provincia Eclesiástica de Acapulco en respuesta a la violencia que deriva de las organizaciones criminales y el deterioro de la vida social. Acapulco, Guerrero. México. 24 de enero de 2008. 
res, violencia común sobre todo en la periferia de las grandes ciudades, violencia de grupos juveniles y creciente violencia intrafamiliar". ${ }^{32}$

La Arquidiócesis Primada de México, a través del Cardenal Norberto Rivera Carrera, llamó a través de su semanario "Desde la Fe" a no bajar la guardia contra el narcotráfico y reiteró su llamado a que ese grupo cambie pues, de lo contrario, la violencia y destrucción que ejerce tarde o temprano se le revertirá. ${ }^{33}$

Comentaban en dicha ocasión que "no es momento de bajar la guardia, la violencia descontrolada muestra ya la desesperación de todos esos grupos, cada vez más debilitados y presionados por las fuerzas del orden". Consideran los obispos mexicanos que el combate al crimen organizado es un asunto de todos y que requiere de la participación de los distintos niveles de Gobierno, las corporaciones de seguridad, los medios de comunicación, las asociaciones religiosas y en general toda la ciudadanía. "En la guerra contra ese flagelo no deben prevalecer los colores partidistas o intereses políticos" ${ }^{\prime 34}$.

Asimismo destacan la importancia de la prevención contra las adicciones y de la denuncia ciudadana y periodística contra los microtraficantes, "que envenenan a los jóvenes y adolescentes en los barrios y cerca de las escuelas o en los antros".

La Conferencia Episcopal Peruana reunida en Lima, el 17 de junio del 2008, señalan: "que la producción y tráfico de drogas es un grave flagelo para la humanidad, porque además de destruir la vida de millones de personas, provoca la destrucción progresiva del mayor pulmón del planeta y reserva de biodiversidad:

32 Documento Conclusivo. V Conferencia General del Episcopado Latinoamericano y del Caribe. Aparecida. Brasil. № 78. Página 71.13 al 31 de mayo de 2007. Ediciones de la Conferencia Episcopal de Chile. Julio 2007.

33 www.informador.com.mx/mexico. Fecha de Acceso: viernes 12 de septiembre de 2008. 16:40 horas.

34 Ibíd. 
la selva amazónica, y contamina gravemente las aguas de los ríos". ${ }^{35}$

En la actualidad el narcotráfico es el más serio desafío al orden social y moral y a la estabilidad de las instituciones de México, pues su poderío económico puede corromper a todos y su nivel de violencia es muy fuerte. "La situación por la que atraviesa el país es sumamente grave y muestra de ello son los recientes atentados y asesinatos de altos mandos de las corporaciones especializadas para combatir a estos criminales. Parecería que nada los detiene". Sin embargo, los obispos mexicanos terminan diciendo que la sociedad no puede seguir viviendo oprimida bajo el yugo de una civilización contraria a la vida, es decir en medio de una cultura de la muerte.

En este mismo tenor, el Arzobispo de la Arquidiócesis de Santiago, Monseñor Francisco Javier Errázuriz Ossa, en su homilía en el Te Deúm Ecuménico celebrado el jueves 18 de Septiembre de 2008, en la Catedral Metropolitana dijo: "Hemos querido que se erradique la corrupción y también el narcotráfico, y hemos puesto una gran esperanza en la justa respuesta a la aspiración que tienen todos los jóvenes y los niños de recibir una educación de calidad. Queremos que no se recurra a la violencia para solucionar los problemas, sino al diálogo y al respeto de los derechos de los demás, de manera que haya paz en las familias, paz en las aulas, en las empresas, en las poblaciones, en los estadios, en los campos y en los bosques, y siempre entre los países ${ }^{\prime \prime 36}$.

Otra faceta de este problema endémico son las declaraciones que diera el Obispo de Texcoco, Carlos Aguiar Retes, en la clausura de la 85 Asamblea Plenaria de la Conferencia Episcopal

35 Obispos del Centro del Perú se pronuncian contra el Narcotráfico y la Violencia. Conferencia Episcopal del Perú. Lima. Junio 2008. www.zenit.org. Fecha de Acceso: 19 de septiembre de 2008. 17:20 horas.

36 Cardenal Francisco Javier Errázuriz: “Y nosotros ¿qué buscamos?” Homilía Te Deum Ecuménico 2008. Catedral Metropolitana de Santiago de Chile el 18 de Septiembre de 2008. www.iglesia.cl. Fecha de Acceso: viernes 20 de septiembre de 2008. 11:05 horas. 
Mexicana (CEM), reabriendo un antiguo debate que atañe directamente a la iglesia católica: las narcolimosnas. Y es que el Obispo Retes exaltó la generosidad de algunos narcotraficantes y fue más lejos todavía: manifestó que en México debería aprobarse una ley que permita a los delincuentes arrepentirse de sus actos y reintegrarse a la sociedad. ${ }^{37}$

Abundó el también presidente de la CEM: "Los narcotraficantes hacen obras muy significativas para la comunidad: meten luz y se encargan de financiar la construcción de caminos. También construyen iglesias y capillas. Eso ocurre en algunos pueblos muy remotos de la sierra, donde el gobierno no tiene recursos para actuar".

Las reacciones a lo dicho por el obispo de Texcoco no cayeron bien a la jerarquía católica mexicana. El Secretario General de la CEM, Monseñor José Leopoldo López, matizó las declaraciones formuladas por el Obispo Retes al comentar que éste no se refería a narcotraficantes, sino a delincuentes menores que no podían retirarse del hampa por estar amenazados.

La CEM también fijó su posición en relación con el tema. En un comunicado, dijo: "Nos extraña que militantes de algunos partidos políticos, de organismos sociales y de la misma clase intelectual, que, sin conocer el contexto de las declaraciones hechas por Monseñor Aguiar, hagan comentarios sobre un tema tan delicado como es el llamado a un cambio de vida".

Días después, el órgano oficial de la Arquidiócesis Primada de México, Desde la fe, publicó un artículo, en el que subraya que la Iglesia Católica condena las actividades ilícitas del narcotráfico. Y asegura que las declaraciones del obispo Aguiar Retes fueron sacadas de contexto.

37 Arturo Rodríguez García. Las Narcolimosnas. www.proceso.com.mx. Fecha de Acceso: viernes 19 de septiembre de 2008. 11:25 horas. 
Entrevistado al respecto, el obispo Raúl Vera, una de las voces independientes dentro de la Iglesia Católica de México, comenta que el presidente de la CEM habló a título personal porque ese tema no fue objeto de discusión en la Asamblea.

Sin embargo, reprueba que la Iglesia Católica acepte narcolimosnas porque, en su opinión, éstas no representan ningún gesto de generosidad de los donantes, sino que forman parte de una estrategia del crimen organizado para lavar dinero. Es más, sostiene que debe castigarse a los sacerdotes que reciben narcolimosnas con pleno conocimiento de causa, porque lo que están haciendo, en realidad, es lavar dinero del narcotráfico.

El Obispo de Saltillo considera que hay una falsa premisa en la Iglesia de que el dinero malo se hace bueno porque se invierte en cosas buenas. "El problema grave del narco es que se trata de un pecado social. Un negocio que tiene por objetivo afectar la vida de las personas, al poner a su alcance un veneno que, luego, desbarata familias y, en consecuencia, la estructura social.

Según Vera, los mecanismos que tiene el negocio del narcotráfico implican una estela de corrupción por donde quiera que se le vea. Además, desde el punto de vista moral, es imposible decir que se limpia el dinero, sólo porque se pone carpeta al pavimento, un jardín a un pueblo o se arregla una capilla. Por todo el conjunto de acciones, es un pecado social". ${ }^{38}$

Sobre lo dicho por Aguiar Retes en el sentido de que sólo Dios puede juzgar y perdonar a los narcos, el Obispo de Saltillo responde: "Eso es delicado y grave: La Iglesia no puede prestarse, conscientemente, a recibir un donativo que viene del narco. $Y$ no sólo de eso, sino del dinero que proviene de trata de blancas, de humanos, de las armas. Hay pecado social en el que la iglesia no puede formar parte, en el orden de una institución que tiene que ayudar a la verdad y la justicia. "Si un sacerdote se presta al

38 Ibíd. 
lavado de dinero, entramos al terreno criminal y eso es fatal. $\mathrm{Si}$ un Obispo se entera de que el padrecito está recibiendo dinero, no se puede quedar, porque estaría entrando también al manejo criminal".

Vera afirma que la Iglesia no puede proteger a los narcotraficantes. "Aquí hablamos del crimen organizado, de ninguna manera en el caso de nosotros como sacerdotes, podemos erigirnos en colaboradores del Ministerio Público, pero tampoco podemos ser protectores del crimen organizado ¡nomás eso faltaba! "Jamás. La Iglesia no va a ayudar al Ministerio Público, eso sería absurdo; pero tiene sus obligaciones en la persecución de un delito, que es punible y que tiene y ha llegado a alterar el orden público, bajo ninguna circunstancia se puede erigir en protectora de criminales".

Relacionarse y aceptar ayuda del narcotráfico, tiene dos rutas desde la perspectiva de Raúl Vera: la primera y la más importante es, dice, la cuestión moral y religiosa. Y, la segunda, es ante la justicia terrena. "Para que alguien involucrado se zafe delante de Dios es muy difícil, porque es mucha violencia sobre la sociedad". El obispo se explaya: "Si una persona quiere obtener los frutos de la revolución cristiana, tiene que reparar el daño".

Con base en ese precepto, considera que un narcotraficante que dejó huérfanos y viudas y que provocó daño en vida, debe repararlo, no directamente, pero debe reparar el daño social, debe pagar la deuda social que tiene. Para terminar con ese debate, Vera López propone que se transparenten los ingresos de la iglesia.

El representante de la Iglesia al preguntarle responde: "Que yo sepa, una propuesta como tal no. Pero creo que no es difícil saber, normalmente andamos a las alcanzadas. Siempre veo a los padres todos amolados. Si los padres recibieran dineros descomunales sería notorio. ¿Es viable transparentar los recursos de la Iglesia? Vera dice que no sólo es viable, sino que es recomen- 
dable. "Hay diócesis más disciplinadas que otras y párrocos más disciplinados que otros. Los sacerdotes siempre están realizando obras y el dinero que reciben, los donativos, son un asunto muy delicado, tenemos que tener mucha pulcritud". Y remata: "el dinero sucio no se limpia". ${ }^{39}$

En nuestro país las iglesias cristianas, tanto católica como evangélicas, firmaron un trascendente marco de acuerdo para enfrenar el flagelo del tráfico y consumo de drogas. En dicha ocasión, la Presidenta de la República, Dra. Michelle Bachellet Jeria, sostuvo que el combate a las drogas es una tarea país, "en la que deben confluir todos los sectores e instituciones, dada la complejidad del problema y la diversidad de quienes lo sufren".

La Mandataria valoró, asimismo, la labor de las iglesias en el ámbito social. "Conozco bien la labor de las Iglesias Cristianas y sé de sus esfuerzos destinados a guiar a muchas personas en la búsqueda de un sentido profundo de la existencia humana, como también de las razones para integrarse a una sociedad y desarrollar una vida digna y provechosa", manifestó. Del mismo modo, expresó que "las Iglesias también se han pronunciado con mucha fuerza respecto de la desigualdad de nuestra sociedad y tienen una poderosa presencia en la lucha contra la pobreza y la discriminación" ${ }^{40}$

\section{Ley $N^{\circ}$ 19.638 Sobre "constitución jurídica y funcionamiento de las iglesias y organizaciones religiosas"}

Hoy en Chile las entidades religiosas cuentan con una ley que les favorece en el sentido de contar con reconocimiento jurídico de carácter público, otorgándoles a las iglesias un tremendo espacio

39 Ibíd.

40 Ver la intervención de la Presidenta Dra. Michelle Bachellet Jeria. Mandataria: Las políticas públicas funcionan cuando los ciudadanos se hacen parte de ellas. Lunes, 21 de abril de 2008. http://www.gobiernodechile.cl/viewNoticia. aspx?idArticulo=23134. Fecha de Acceso: sábado 20 de septiembre de 2008. 18:31 horas. 
de acción como también de omisión al poder amparar en su memento asociaciones ilícitas que ocupen este "paragua jurídico" para actuar libremente.

Para el abogado y sociólogo Humberto Lagos Schuffeneger, "es un hecho que el tema de la Personalidad Jurídica de Derecho Público constituye un asunto central cuando de la igualdad ante la ley, en el campo religioso, se trata" ${ }^{41}$ No obstante lo anterior, desde que el Presidente Eduardo Frei Ruiz-Tagle promulgara la Ley N 19.638, en el Diario Oficial el 14 de octubre de 1999, rompe el esquema de tolerancia religiosa para sentar el derecho al reconocimiento de la calidad de personas de derecho público de las Iglesias y Organizaciones Religiosas que lo soliciten. ${ }^{42}$

Antes de 1999, las iglesias evangélicas se podían acoger al llamado Decreto Reglamentario 110, el que permite que entidades sociales y civiles se pudieran constituir como personas de derecho privado sin fines de lucro.

De la misma forma, la aplicación de la ley $\mathrm{N}^{0} 19.638$, que norma la constitución de iglesias y organizaciones religiosas, que beneficia la posición histórica de la Iglesia Católica, Apostólica y Romana, sobre la base de dudosos y cuestionables argumentos y derechos, sustentados en una personalidad jurídica arbitraria y de clara condición hegemónica (personalidad de Derecho Público y estatuto interno regulado por legislación extranjera), que permite en los hechos una especie de reoficialización, sobre la base de una ventaja jurídica frente a las religiones emergentes o credos minoritarios.

Ante la constatación de la existencia de una religión que posee una Personalidad Jurídica de Derecho Público, calidad atribuible solo a los órganos encargados de la administración del

41 Humberto Lagos Schuffeneger. La Libertad Religiosa en Chile: Mitos y Realidades. Revista Occidente. N 398. Abril-Junio 2008. Página 43.

42 Humberto Lagos Schuffeneger. Chile y el Mito del Estado Laico. Ediciones Ixthus. Santiago. Chile Enero 2005. Página 52. 
Estado, queda de manifiesto el mito del Estado Laico en absoluta evidencia, producto de la contradicción que ello implica, toda vez que se entiende que las personas jurídicas de derecho público son atribuibles solo al ámbito de actividades y órganos que realizan o norman entes oficiales. Las entidades de derecho público deben perseguir un fin público, y por lo tanto tienen que pertenecer a las estructuras políticas y administrativas del Estado. Deben ser creadas por ley y cumplir fines propios del Estado, con los controles administrativos, la potestad y la organización pública. ${ }^{43}$

Esta ley se ha transformado en un verdadero paraíso para aquellos que con un legítimo derecho han accedido a una posición jurídica de derecho público, que en sí no es negativo. El problema se centra en aquellas entidades de carácter religioso que optan a este reconocimiento legal y pueden caer en la tentación de poner a disposición de asociaciones ilícitas su personalidad jurídica de derecho público.

\section{A modo de conclusión}

Concluimos nuestro ensayo con las palabras del teólogo suizo Hans Küng ${ }^{44}$, quien dice que la lucha contra la corrupción debe emprenderse con todos los medios legales. Y a menudo no hay ninguna voluntad política de combatir la corrupción porque detrás no hay una voluntad ética; y muchas disposiciones legales contra la corrupción no se aplican en la práctica por la falta de una conciencia de injusticia, ya que es habitual que se hayan perdido las pautas éticas elementales, tanto en la población en general como en las elites. Sostiene Hans Küng que la reforma de un Estado suele ser muy difícil porque falta una base ética. ${ }^{45}$

43 Sebastián Jans. La Personalidad Jurídica de la Iglesia Católica en Chile. Voz el diario electrónico Mundo.com. Un diario de alcance mundial. http://www.vozalmundo. com/index.php?id=4913. Fecha de Acceso: lunes 15 de septiembre de 2008. 20:19 horas.

44 Ver a Hans Küng. Una Ética Mundial para la Economía y la Política. Editorial Trotta, S.A. Madrid. España. 1999.

45 Hans Küng. La Lucha contra la Corrupción Requiere un Marco Ético. En: Peter Eigen. Las Redes de la Corrupción: La Sociedad Civil Contra los Abusos del Poder. 
Por ello, proponemos un marco de referencia ético propuesto por John Dunning ${ }^{46}$, sin el cual es muy difícil de poder combatir la corrupción.

Una estructura comercial inadecuada en el ámbito de las macro organizaciones va ligada a la falta de honradez y al fraude, así como a la falta de confianza, de capacidad de compromiso, de cooperación y de lealtad de grupo.

Las insuficiencias en el sistema jurídico, por ejemplo respecto a la prevención de delitos, están asociadas al capitalismo de casino y de mafia.

Un sistema bancario, financiero y de contabilidad inadecuado tiene que ver con oportunismo, dejadez e indisciplina.

Una organización social inadecuada va ligada a la indiferencia hacia las necesidades de los demás y una falta de sentido del deber personal y de la responsabilidad social.

Una ausencia de control en organizaciones religiosas que acceden al registro de personalidad jurídica de derecho público, creándose vacíos en donde asociaciones ilícitas pueden usarlas para sus beneficios particulares, tanto lavado de dinero como tráfico de drogas.

De todo esto, podemos deducir que la ética no es algo marginal o algo añadido artificialmente, sino que aquí se habla con pleno derecho de un marco moral que se halla en interdependencia e interacción tanto como los mercados como los gobiernos, tanto con las asociaciones intermedias como con las organizaciones supranacionales.

Al hablar de ética, no nos referimos sólo a una invocación de la moral, sino a una manera de obrar moral. Obrar que debe dar

$1^{a}$ edición. Editorial Planeta. Buenos Aires. Argentina. Septiembre de 2004. Página 251.

46 Ibíd. Página 253. 
cuenta de los principios y valores de servicio público, característica propia de personas probas y de buenas prácticas.

La única forma en que los consagrados al ministerio pastoral puedan enfrentar las tentaciones del crimen organizado es a través de una conducta proba. Por ello, consideramos que a los menos se deben observar las siguientes ideas fuerzas:

Probidad Profesional. Es esencialmente ético que quien puede dar tres no se contente con dos.

Probidad Personal. Si todos caen no se justifica que yo caiga.

Probidad Institucional. Depende de cómo vivamos en el ecosistema que está a nuestro alrededor.

Ética Social. Se debe conocer no solo la historia de nuestro país, sino cómo vivimos y cómo pensamos para entender nuestro entorno y poder intervenirlo adecuadamente.

En suma, hemos sido llamados a servir y no a servirnos de los demás. ${ }^{47}$

\section{Bibliografía}

Águila, F.; Saavedra, O.; Reed, P. (S.F.). Los Movimientos, Contactos y Roles de los Miembros de la Banda de los $₫$ Guatones $\llbracket$. Captura de Organización Proveedora de Cocaína en la Zona Sur de Santiago. www.el mercurio.com. Santiago. Chile.

Bachellet Jeria, Michelle (2008) Mandataria: Las políticas públicas funcionan cuando los ciudadanos se hacen parte de ellas. Lunes, 21 de abril de 2008. http://www.gobiernodechile.cl/viewNoticia.aspx?idArticulo $=23134$

Berdal, Mats y Serrano, Mónica (compiladores) (2005). Crimen Transnacional Organizado y Seguridad Internacional: Cambio y Continuidad. Fondo de Cultura Económica. México.

Calvani, Sandro. Rol de las Naciones Unidas (UNODC) en la lucha contra la delincuencia organizada transnacional, el terrorismo y la corrupción. www.sandrocalvani.com.

47 David Muñoz Condell. Definición y Aplicación del Concepto Ético a la Función Pública. Diplomado Virtual Latinoamericano en Descentralización y Desarrollo Local Regional. Universidad Alberto Hurtado. Santiago. Chile. Junio 2008. 
Castell, Manuel (2005). Globalización, Desarrollo y Democracia: Chile en el Contexto Mundial. Fondo de Cultura Económica. Santiago. Chile.

Conferencia Episcopal de Chile (2007). Documento Conclusivo. V Conferencia General del Episcopado Latinoamericano y del Caribe. Aparecida. Brasil. Santiago de Chile.

Conferencia Episcopal del Perú (2008). Obispos del Centro del Perú se pronuncian contra el Narcotráfico y la Violencia. Junio 2008. Www.zenit.org

Cooper, Doris (2005). Delincuencia y Desviación Juvenil. 1ª edición. Ediciones LOM. Santiago. Chile.

Díaz Prieto, Felipe y López, Andrés (2008). Banda de Narcotráfico financiaba templo evangélico y colegio. Sección Nacional. Diario La Tercera. Santiago. Chile. 23 de julio del 2008. www.latercera.cl.

Eigen, Peter (2004). Las Redes de la Corrupción: La Sociedad Civil Contra los Abusos del Poder. $1^{\text {a }}$ edición. Editorial Planeta. Buenos Aires. Argentina.

Errázuriz, Cardenal Francisco Javier (2008). "Y nosotros ¿qué buscamos?" Homilía Te Deum Ecuménico 2008. Catedral Metropolitana de Santiago de Chile el 18 de Septiembre de 2008. www.iglesia.cl

Goic Karmelic, Alejandro (2008). La Iglesia ante la Droga. Conferencia Episcopal de Chile. Santiago. Chile.

Herrera Verdugo, Arturo (2004). Cuenta Pública $71^{\circ}$ Aniversario de la Policía de Investigaciones de Chile. Santiago. Chile. 19 de junio 2004.

Jans, Sebastián (S.F.). La Personalidad Jurídica de la Iglesia Católica en Chile. Voz al Mundo el diario electrónico. http: / / www.vozalmundo.com/index.php?id=4913

Küng, Hans (1999). Una Ética Mundial para la Economía y la Política. Editorial Trotta, S.A. Madrid. España. 1999.

(2004). La Lucha contra la Corrupción Requiere un Marco Ético. En: Peter Eigen. Las Redes de la Corrupción: La Sociedad Civil Contra los Abusos del Poder. $1^{\mathrm{a}}$ edición. Editorial Planeta. Buenos Aires. Argentina.

Lagos Schuffeneger, Humberto (2005). Chile y el Mito del Estado Laico. Ediciones Ixthus. Santiago. Chile.

(2008). La Libertad Religiosa en Chile: Mitos y Realidades. Revista Occidente. Nº 398. 
Leiva Cortés, Claudio (S.F.). Cae Banda que proveía de cocaína a 『Los Cavieres囚. Diario La Nación. Santiago Chile. www.lanacion.cl

Mesa, David (2008). Cuenta Pública 2007-2008, Jefatura Nacional Antinarcóticos. Policía de Investigaciones de Chile. Santiago. Chile.

Muñoz Condell, David (2005). Ética, Modernidad y Postmodernidad. Documento de Trabajo $\mathrm{N}^{\circ} 111$. Escuela de Investigaciones Policiales. Santiago. Chile.

Pardo Mateos, Rafael (2007). Fenomenología del Delito: Delincuencia Tradicional y Nuevas Formas de Delincuencia. En VVAA. Elementos Básicos de Investigación Criminal. Instituto Universitario General Gutiérrez Mellado de Investigación sobre la Paz, la Seguridad y la Defensa. Madrid. España.

Rodríguez García, Arturo (S.F.). Las Narcolimosnas. www.proceso.com.mx

Salazar, Manuel (2008). Conexiones Mafiosas: El Crimen Organizado a las Puertas de Chile. Sociedad Editorial Momentum. Santiago. Chile.

(1996). Traficantes \& Lavadores. Ediciones Grijalbo. México.

Sánchez García de Paz, Isabel. La Criminalidad Organizada. Aspectos Penales, Procesales, Administrativos y Policiales. Dykinson. España. 2005.

Szczaranski, Clara (2008). La Delincuencia Moderna, Prólogo del libro de Manuel Salazar. Conexiones Mafiosas: El Crimen Organizado a las Puertas de Chile. Sociedad Editorial Momentum. Santiago. Chile. $1^{\text {a }}$ edición.

VVAA (2004). Prevención de la Delincuencia Juvenil. Análisis de experiencias internacionales. División de Seguridad Ciudadana, Ministerio del Interior. República de Chile. Universidad Alberto Hurtado. $1^{a}$ edición. Santiago. Chile. Marzo 2004. 